\title{
TRABALHO LIVRE, TRABALHO ESCRAVO: EXPERIÊNCIAS EM COMUM
}

\author{
MATTOS, Marcelo Badaró. Laborers and Enslaved Workers: Expe- \\ riences in Common in the Making of Rio de Janeiro's Working Class, \\ 1850-1920. Nova York: Berghahn Books, 2017. 175p.
}

$A$ versão em inglês do livro de Marcelo Badaró Mattos é um feito da história social brasileira em seu notável esforço de reconhecimento de excelência internacional. ${ }^{1}$ Debruçado sobre contexto específico - a cidade do Rio de Janeiro entre a segunda metade do século XIX e as primeiras décadas do século $\mathrm{XX}-$, o livro prossegue com a proposta de E. P. Thompson de derrubar as muralhas separadoras da história da agitação da classe trabalhadora da história cultural e intelectual do resto da nação (como está afirmado na Formação da classe trabalhadora inglesa, em seu prefácio). Como resultado, Mattos protagoniza um momento característico da historiografia brasileira, que é o foco na coexistência de trabalhadores livres e libertos, trabalhadores escravizados, ou não-livres. (Ou, simplesmente, trabalhadores.)

1 Edição brasileira do livro: Marcelo Mattos, Escravizados e livres: experiências comuns na formação da classe trabalhadora carioca, Rio de Janeiro: Bom Texto, 2008.
Ao considerar a classe como processo e como uma relação - e não como um dado da estrutura social -, Mattos esclarece ser infrutífero voltar atrás no tempo apenas em busca de experiências de trabalhadores livres.

Movendo-se para fora dos campi universitários e tocando os corações e mentes de pessoas comuns - particularmente a juventude e professores nas escolas, mas também ativistas de movimentos sociais -, uma saliente contribuição dessa obra ao Brasil contemporâneo está em chamar a atenção para o fato de seres humanos terem sido escravizados, uma modificação necessária no jeito como a história brasileira tem sido percebida e contada. Uma sutil mudança no léxico (de "escravos" para "trabalhadores escravizados", sendo este último pouco utilizado até recentemente) sublinha a dignidade, o valor e a ação de homens e mulheres negros que foram submetidos ao cativeiro. Além disso, esta tradução vem à luz em uma 
conjuntura mundial muito delicada: a guinada à direita fascista. $\mathrm{O}$ escravismo e seu legado de desigualdade e trabalho não-livre ou não-pago são assuntos altamente sensíveis da política (não apenas no Brasil).

O livro é, no entanto, controverso. Na sua abordagem do abolicionismo, ao apontar a limitação da via legal disponível rumo à liberdade, por meio das alforrias, bem como os resultados de ações em juízo após cerca de dez a quinze anos desde 1871 e, como efeito disso, a conversão dos abolicionistas a um "modo mais consequente de lutar" (p.106), Mattos tenta criar um ponto de virada na trajetória de um processo complexo, que não é retilíneo nem se divide em um antes e depois de uma (alegada) inflexão. $\mathrm{O}$ que $\mathrm{o}$ autor sustenta ser um limite restritivo, pode ter sido superado, não pelo seu abandono em favor de algo melhor, mas por sua combinação a outras iniciativas. Ao nutrirem suas experiências, expectativas e valores coletivos, os trabalhadores negros e abolicionistas tinham os seus próprios meios para confrontar a instituição da escravidão e ir além da dicotomia entre "uma liberdade inacabada do ponto de vista daqueles que lutaram pela emancipação humana em seu sentido amplo" e a proposta de por fim à "divisão da sociedade em classes" (p. 161). Aqui, por exemplo, vale a pena recordar Wlamyra Albuquerque, que reparou no abolicionismo dos de baixo, em paralelo ao abolicionismo observado por Mattos.
Alinhando fugas de escravos, lideranças populares e trabalhadores urbanos, havia em jogo possibilidades de ruptura muito diferentes do cardápio servido na mesa bem posta do "banquete da civilização". Elciene Azevedo, por sua vez, percebeu possibilidades extraordinárias, mesmo no intrincado domínio da lei, revelando a existência de um abolicionismo radical. Em ambas as pesquisas, vieram à tona esforços de efetivação imediata de experiências de liberdade, perturbando os senhores, não apenas pelo recurso ao judiciário, mas também pela possibilidade da difusão do mundo de cabeça para baixo. Walter Fraga, em acréscimo, nota na figura de Ismael Ribeiro dos Santos uma possibilidade de trânsito ou continuidade, pincelando os laços entre abolicionismo e movimento operário. Fraga inclusive cogita que trabalhadores na Bahia estivessem testando a validade de "agir como classe". Não, portanto, a conversão de uma coisa à outra, a primeira, obsoleta, superada, ultrapassada pela segunda; mas, antes, experimentos, medidos na pressão pelos sujeitos. Sobre estes, Aldrin Castellucci demonstrou como a defesa do ofício da parte de trabalhadores negros qualificados (profissionais aliás materialmente bem sucedidos) era uma forma de sustentar conquistas do trabalho livre mesmo em vizinhança - ou "envolvimento" com a política oligárquica. ${ }^{2}$

2 Wlamyra Albuquerque, O jogo da dissi- 
Também é difícil notar, no livro em tela, quando ou onde a classe trabalhadora foi de fato formada. Primeiro, a formação da classe é um processo nacional, matéria não contemplada no recorte feito pelo autor. Que o Rio é a capital é evidentemente um fator de peso, mas, apesar disso, e considerando o fato do Rio ter sido o sítio mais industrializado do início do século $\mathrm{XX}$, não está claro se a formação da classe no Rio é um processo peculiar ou um paradigma para todo o país seguir. E também se poderia indagar, sobre o Rio mesmo, das conexões com os trabalhadores rurais, os escravizados em particular, nas fazendas; ou ainda os quilombolas do "campo negro" que Flávio Gomes vinculou à "cidade negra" descrita por Sidney Chalhoub, detectando inaudito e poderoso trânsito entre cativeiro e liberdade. ${ }^{3}$

Alinhado a Thompson como Mattos é, em algum ponto deveria

mulação: abolição e cidadania negra no Brasil, São Paulo: Companhia das Letras, 2009, p. 82; Elciene Azevedo, O direito dos escravos: lutas jurídicas e abolicionismo na província de São Paulo, Campinas: Editora da Unicamp, 2010, p.32; Walter Fraga Filho, Encruzilhadas da liberdade: histórias de escravos e libertos na Bahia, 1870-1910, Campinas: Editora da Unicamp, 2006, p. 106, 340; Aldrin Castellucci, Trabalhadores e politica no Brasil: do aprendizado do Império aos sucessos da Primeira República, Salvador: Editora da Uneb, 2015, p. 21.

3 Robert Slenes, "O escravismo por um fio?", apud Flávio Gomes, A hidra e os pântanos: mocambos, quilombos e comunidades de fugitivos no Brasil (séculos XVII-XIX), São Paulo: Polis, 2005, p. 15. haver uma reflexão sobre um momento em que a classe trabalhadora está formada. Se o caso inglês for levado em conta, a presença da classe trabalhadora, a partir de 1832, foi sentida em todos os condados. E na maioria dos campos da vida, é literalmente dito. Portanto, ideias, atitudes e experimentos amadureceram antes mesmo do cartismo (e antes de sindicatos de trabalhadores industriais ou partidos políticos operários), do que 1832 foi uma prefiguração. Esta, como um fenômeno, foi uma demarcação consciente em um processo de autodescoberta e autodefinição. Em contraste, na narrativa de Mattos, o declínio da escravidão no Brasil é acompanhado pela insinuante proletarização de artesãos em uma nova classe de trabalhadores assalariados nas fábricas. A proteção da respeitabilidade do ofício, argumenta ele, contribuiu para aproximar artesãos e braçais (p. 155). Greves, pontua, são deflagradas na década de 1890 (após o fim da escravidão em 1888) e continuam no século seguinte. Nos primeiros anos da década de 1910, as greves "já eram uma experiência generalizada, partidos trabalhistas/socialistas haviam surgido e as instituições sindicais da classe já estavam constituídas com relativa estabilidade" (p. 6). Neste sentido, uma semelhança pode ser observada entre o "caso europeu" (p. 7, 126) e o carioca.

$\mathrm{O}$ autor enfatiza o caráter estratégico de sindicatos e partidos em cujas mãos cabe a tarefa de criar uma "sucessão de estágios ou níveis" - "o 
nível econômico-corporativo, a solidariedade de classe na esfera econômica e a consciência do projeto de classe" - a fim de trazer à tona a maturidade do proletariado (p. 134). Sua atenção como pesquisador está voltada para os discursos dos trabalhadores, em particular os escritos, encontrados principalmente na imprensa operária. Contudo, como a consciência de classe é uma formação cultural, a voz radical da liderança não deve obscurecer as características elusivas do inarticulado, a cultura popular ou seus códigos não escritos. Por fim, cabe indagar o quanto a chegada de imigrantes no Rio serviu mais para dividir ou desfazer o associativismo operário já existente do que mobilizar a classe operária. ${ }^{4}$

Mattos tem parte destacada nos ganhos que a pesquisa histórica proporciona quando certas situações são consideradas: quer quando os trabalhadores são sujeitos no cotidiano, quer quando são perseguidos como desviantes: encrenqueiros, fugitivos, fetichistas; enfim, classes perigosas. Quando trabalhadores escravizados ou livres eram alvo de pressões inibidoras vindas de cima, eles respondiam com sua preferência por valores horizontais de lealdade, camaradagem, festa e prazer. E tudo isso é relevante para o autor. Sua menção aos africanos que desembarcam em posse de habilidades relevantes para os

4 Paulo Fontes e Francisco Macedo, "Entrevista com Michael Hall", Estudos históricos, v. 29, n. 59 (2016), p. 829, 830. ofícios para os quais foram obrigados (p. 21) é um convite encorajador à pesquisa. Mas depois ele não abre espaço para um paralelo com a ideia do inglês livre ao nascer, já que, como ele afirma, "a liberdade era algo recente" (p. 155). Contudo, tal qual ingleses, os trabalhadores africanos escravizados, ou aqueles ilegalmente escravizados, sabiam que haviam nascido livres, e que o eram por direito.

A ênfase na afinidade entre o movimento operário carioca e o europeu (termos desiguais, vale dizer) - ambos protagonizados por proletários livres assalariados, ressaltados no avançar da industrialização - não pode no entanto deixar de lado sua importante afirmação sobre ser infrutífero fazer pesquisa histórica em busca de trabalhadores livres apenas. Como tem sido sublinhado amplamente, capitalismo e cativeiro são cônjuges de uma História de amor global. Não só os escravizados, os libertos e os reescravizados tinham lutas concretas contra a exploração e a injustiça como também, hoje em dia, parece ser uma miragem o trabalho livre com direito, na prática, a um sindicato para defendê-lo do patronato e também a um partido para representá-lo no parlamento (ou fazer a revolução). Em paralelo às lutas socialistas ou à construção de um Estado de bem-estar social, a pesquisa tem revelado a obsessão das classes dominantes em reforçar a supremacia racial como uma forma de dominar a mão de obra dos trabalhadores, 
aprisionando-a em relações tóxicas. De fato, referindo-se à - legal ou ilegal - "falta de liberdade da força de trabalho", Julius Scott observa que trabalhadores chamados de "livres" podem ser mais "anomalia" do que "regra". E, então, é do maior relevo observar (como fez Robério Souza) que, assim como a ferrovia britânica na Bahia na década de 1860 não fez questão de discernir se os trabalhadores eram livres ou escravizados, as ferrovias construídas por trabalhadores negros nos Estados Unidos não se inquietavam se eram livres ou cidadãos de segunda classe, ou uma nova forma de escravizados, inventada para (quase imediatamente) suceder o fim da escravidão. ${ }^{5}$

5 Julius Scott, The Common Wind: Afro-American Currents in the Age of the Haitian Revolution, Londres: Verso, 2018, p. 2, 3; Robério Souza, Trabalhadores dos trilhos: imigrantes e nacionais livres, libertos e escravos na construção da primeira ferrovia baiana (1858-1863), Campinas: Editora da Unicamp, 2015; e Douglas Blackmon, Slavery by Another Name: The Re-enslavement of Black Americans from the Civil War to World War II, Nova York: Doubleday, 2008, p.7.
O livro de Mattos é um acontecimento saliente na "especial ênfase da historiografia brasileira em combinar História da escravidão e história do trabalho "livre", conforme Weinstein percebeu e registrou. ${ }^{6}$ Quer fossem trabalhadores em fábricas, quer fossem prostitutas nas janelas, morigerados ou ladrões, tipógrafos ou estivadores, ou padeiros, a classe operária carioca transmitiu através das gerações os valores de independência e autodefesa. Se existe alguma modernidade no mundo contemporâneo, as conquistas do socialismo e do bem-estar social também devem ser notadas nas experiências de homens e mulheres trabalhadores que deram origem a uma presença única na sociedade, antes mesmo de os trabalhadores no Rio de Janeiro começarem a se comportar de maneira muito semelhante ao que tinha sucedido no Atlântico Norte.

6 Barbara Weinstein, "Globalizando a História do Trabalho: o caso da revista International Labor and Working-Class History", Mundos do trabalho, v. 9, n. 18 (2017), p. 18.

Antonio Luigi Negro

Universidade Federal da Bahia negro@ufba.br 